\title{
Drug-resistant pulmonary tuberculosis in Berlin, Germany, 1987-1993
}

\author{
T. Schaberg*, G. Gloger*, B. Reichert**, H. Mauch**, H. Lode*
}

\begin{abstract}
Drug-resistant pulmonary tuberculosis in Berlin, Germany, 1987-1993. T. Schaberg, G. Gloger, B. Reichert, H. Mauch, H. Lode. (CERS Journals Ltd 1995.

ABSTRACT: Resistance of Mycobacterium tuberculosis (M.tb) strains is an increasing problem worldwide. Since no public health data are available for urban populations in Germany, we investigated resistance in our hospitalized patients $(n=1,011)$ over the last 7 yrs.

We therefore evaluated clinical data and results of susceptibility tests (breakpoint technique/proportion method) for isoniazid, streptomycin, rifampin, pyrazinamide, protionamide and ethambutol.

Since 1987, there has been a relatively constant rate of $5.9 \%(3.9 \%-7.8 \%)$ for single-drug resistance (SDR), but an increasing rate of multidrug-resistant (MDR) strains ( $\geq 2$ first-line drugs) from $1.7 \%$ in 1987 to $5.8 \%$ in 1993 . Sixty nine percent of patients with MDR strains showed resistance to two drugs, and $31 \%$ to three or more drugs. Risk factors for SDR and MDR tuberculosis revealed previous therapy (odds ratio $(\mathrm{OR})(95 \%$ confidence interval $(95 \% \mathrm{CI})$ ); SDR 2.2 (1.7-4.0); MDR 4.5 (2.3-8.8)); and foreign-born status (SDR 2.2 (1.3-3.6); MDR 3.5 (1.8-6.8)) to be the most important factors associated with resistance. Both primary and acquired resistance were higher in foreign-born than in German-born patients.

We conclude that there was a considerable increase in multidrug-resistant tuberculosis in our hospital from 1987 to 1993 . Since previously treated patients and patients born in countries with a high level of primary resistance had an increased risk of drug-resistant tuberculosis, we would advise a four drug regimen as initial therapy in those patients.
\end{abstract}

Eur Respir J., 1995, 8, 278-284.

\author{
*Section of Infectious Diseases and Immuno- \\ logy, Dept of Pulmonary Medicine, and \\ **Mycobacterial Laboratory, Chest Hospital \\ Heckeshorn-Zehlendorf, Berlin, Germany. \\ Correspondence: T. Schaberg \\ Section of Infectious Diseases and \\ Immunology \\ Dept of Pulmonary Medicine \\ Chest Hospital Heckeshorn-Zehlendorf \\ Zum Heckeshorn 33 \\ D-14109 Berlin-Wannsee \\ Germany
}

Keywords: Multidrug resistance

single-drug resistance

tuberculosis

Received: June 151994

Accepted after revision October 161994
Throughout the decades of 1950-1990, the incidence of reported tuberculosis in Germany declined each year by $5 \%$ [1] to 17.3 per 100,000 in 1991 . A comparable development has been observed in Berlin, although the incidence of tuberculosis in Berlin in 1991 was still considerably higher (25.9 per 100,000), with a peak in the inner city districts of up to 50 per 100,000 (personal communication, State Health Department, Berlin). The rate of resistance in Germany was $<5 \%$ for single-drug resistance, and $<2 \%$ for multidrug resistance between 1972 and 1975 [2], but no exact data are available on the rate of resistance in Berlin or other major cities in Germany. In a recent survey of the years 1991 and 1992, the resistance to standard antituberculosis drugs in all of Germany was found to be $10 \%$ for single-drug resistance (SDR) and 3\% for multidrug resistance (MDR) [3]. The drugs involved in resistance were primarily isoniazid (5.4\%) and streptomycin (4\%) [3].

In the United States, on the other hand, the incidence of tuberculosis increased substantially from 1985 to 1991 [4-6], with a major resistance problem first occurring in human immunodeficiency virus (HIV)-positive patients [7-9]. In 1993, the emergence of multidrug-resistant strains of Mycobacterium tuberculosis (M.tb) was also reported in patients without HIV infection in New York City [10-12]. As the rate of drug resistance of M.tb in the United States is extremely different between rural (SDR 14.4\%; MDR 3.3\%) and urban populations (SDR $33 \%$; MDR 19\%) [13], we wanted to know whether comparable differences could also be observed in Germany. We, therefore, conducted a retrospective study of M.tb resistance in our hospitalized patients with culture-positive tuberculosis between 1987 and 1993.

\section{Methods}

All patients with culture-positive pulmonary tuberculosis hospitalized between 1987 and 1993 were included in our study, with the exception of HIV-positive patients. HIV-positive patients were excluded from this analysis because: 1) no data are available about the HIV status before $1990 ; 2$ ) the number of patients with HIV infection and tuberculosis in our hospital between 1990 and 1993 was consistently low $(\leq 2 \%)$; and 3 ) the possibility of increased transmission in HIV-positive patients is high. In none of the data available on each patient included in this study before 1990, was there any evidence 
of HIV infection, based on history, clinical or laboratory findings at the time of pulmonary tuberculosis.

We used current standards in our diagnostic procedures for tuberculosis $[14,15]$. Most specimens investigated were of sputum (85\%). Fifteen percent of the specimens were obtained by fibreoptic bronchoscopy. The results of susceptibility testing on the first isolate of M.tb in each patient were used in this study. Specimens were investigated by fluorescence microscopy, after acidfast bacteria staining using the auramine fluorescence method [16]. Primary cultures were performed in soluble media (Middelbrook $7 \mathrm{H} 9$ broth) and on solid media (Löwenstein-Jensen) [16-18]. Mycobacterium tuberculosis was identified by standard methods [16, 19]. Susceptibility testing was performed on Löwenstein-Jensen solid medium by the breakpoint technique, using the standard proportion method $[16,17]$. Resistance was diagnosed, if less then $1 \%$ inhibition of the original inoculum of $M$. tuberculosis occurred on Löwenstein-Jensen medium containing the following concentration of antibiotics: isoniazid $(\mathrm{H}) 0.25 \mathrm{mg} \cdot l^{-1}$; rifampin $(\mathrm{R}) 32.0 \mathrm{mg} \cdot l^{-1}$; pyrazinamide (Z) $125.0 \mathrm{mg} \cdot l^{-1}$; ethambutol (E) $1.0 \mathrm{mg} \cdot l^{-1}$; streptomycin (S) $4.0 \mathrm{mg} \cdot l^{-1}$; protionamide (P) $32.0 \mathrm{mg} \cdot l^{-1}$ [17].

Single-drug resistance (SDR) was defined as resistance to one of the drugs tested and multidrug resistance (MDR) as resistance to at least two. Resistance in patients treated previously was defined as presumable acquired resistance, although we did not have exact data about the susceptibility of the M.tb strains at the time of previous therapy. In contrast, all resistance detected in patients without a history of previous treatment was defined as primary resistance due to the transmission of resistant strains of $M$. $t b$.

Clinical and demographic information about the patients was obtained from hospital files, which included chest radiographs, and from practitioners' files. Data were obtained on demographic aspects, radiological presentation of tuberculosis, sputum results of acid-fast staining, results of susceptibility tests, history of previous treatment of tuberculosis, history of alcohol or drug abuse, and social environment.

\section{Data analysis}

Categorial data were compared with $2 \times 2$ contingency tables and the Fisher's exact test using two-tailed p-values. Odds ratios (ORs) were calculated using an approximation of Woolf and 95\% confidence intervals (95\% CI). To compare continuous data, the Student's t-test was used for normally distributed data, otherwise, the Mann-Whitney U-test was used [20]. Values of $\mathrm{p}<0.05$ were considered significant. Statistical analysis was carried out using a commercial statistics program (InStat, GraphPad ${ }^{\mathbb{M}}$ ), San Diego, CA, USA).

For the calculation of ORs we primarily used the data of the entire study population. To control biases based on age, gender, or the time of inclusion into the study, we also used age, gender, and year-of-diagnosis matched controls (for SDR one matched control; for MDR two matched controls), which were selected by computeraided random sampling from the list of all patients. Since both types of analysis did not differ, data derived only from the analysis of the entire study population are presented here, because of their higher statistical validity.

\section{Results}

\section{Patient characteristics}

Between 1987 and 1993, 1,011 patients with culturepositive pulmonary tuberculosis were treated in our hospital, from whom susceptibility results of $M$. $t b$ were available. Clinical and demographic data and the results of susceptibility tests are summarized in table 1 . Among

Table 1. - Characteristics of study population

\begin{tabular}{|c|c|c|c|c|c|}
\hline & All patients & Susceptible & Resistant & SDR & MDR \\
\hline Patient $\mathrm{n}$ & 1011 & 913 & 98 & 59 & 39 \\
\hline Mean age yrs & $45 \pm 5$ & $46 \pm 5$ & $41 \pm 7$ & $39 \pm 9$ & $42 \pm 6$ \\
\hline Sex F/M & $320 / 691$ & $295 / 618$ & $25 / 73$ & $14 / 45$ & $11 / 28$ \\
\hline German-born & $\begin{array}{c}675 \\
(66.7)\end{array}$ & $\begin{array}{c}630 \\
(68.9)\end{array}$ & $\begin{array}{c}45 \\
(45.9)\end{array}$ & 30 & 15 \\
\hline Foreign-born & $\begin{array}{c}336 \\
(33.3)\end{array}$ & $\begin{array}{c}283 \\
(31.1)\end{array}$ & $\begin{array}{c}53 \\
(54.1)\end{array}$ & 29 & 24 \\
\hline Previous treatment & $\begin{array}{c}153 \\
(15.1)\end{array}$ & $\begin{array}{c}122 \\
(13.4)\end{array}$ & $\begin{array}{c}31 \\
(31.6)\end{array}$ & 15 & 16 \\
\hline $\begin{array}{l}\text { Previous treatment } \\
\text { and foreign-born }\end{array}$ & $\begin{array}{c}58 \\
(5.7)\end{array}$ & $\begin{array}{l}39 \\
(4.3)\end{array}$ & $\begin{array}{c}19 \\
(19.3)\end{array}$ & 8 & 11 \\
\hline $\begin{array}{l}\text { Previous treatment } \\
\text { and German-born }\end{array}$ & $\begin{array}{l}95 \\
(9.3)\end{array}$ & $\begin{array}{c}83 \\
(9.1)\end{array}$ & $\begin{array}{c}12 \\
(12.2)\end{array}$ & 7 & 5 \\
\hline Cavitary disease & $\begin{array}{c}476 \\
(47.1)\end{array}$ & $\begin{array}{c}430 \\
(47.2)\end{array}$ & $\begin{array}{c}46 \\
(46.9)\end{array}$ & 27 & 19 \\
\hline Sputum smear positive & $\begin{array}{c}642 \\
(63.5)\end{array}$ & $\begin{array}{c}584 \\
(64.0)\end{array}$ & $\begin{array}{c}58 \\
(59.1)\end{array}$ & 38 & 20 \\
\hline $\begin{array}{l}\text { History of alcohol/drug } \\
\text { abuse }\end{array}$ & $\begin{array}{c}278 \\
(27.5)\end{array}$ & $\begin{array}{c}256 \\
(28.0)\end{array}$ & $\begin{array}{c}22 \\
(22.4)\end{array}$ & 17 & 5 \\
\hline
\end{tabular}

Number of patients, with percentage in parenthesis, related to the total number of each column. F: female; M: male; SDR: single-drug resistance; MDR: multidrug resistance. 
the 1,011 patients, 336 (33\%) were foreign-born, and most came from countries with a known high level of primary resistance. Most foreign-born patients were from Turkey $(n=105)$, Eastern Europe $(n=57)$, other Mediterranean countries $(n=43)$, Africa $(n=27)$, and Asia $(n=61)$. Previous treatment of tuberculosis was reported by 153 patients. Thirty two percent of them were treated for less than 3 months, $17 \%$ for $\geq 3$ to $\leq 6$ months, and $51 \%$ for more than 6 months. Data about the drugs used in the previous treatment were only available from the majority of patients treated in Germany, and therefore, could not be further analysed for the entire study population. Cavitary tuberculosis was found to be equally distributed in patients with susceptible and resistant organisms. Nearly two thirds of all the patients investigated showed acid-fast bacilli by sputum microscopy, again equally distributed among patients with susceptible and resistant isolates. A history of alcohol/drug abuse was seen in $27 \%$ of all patients, with a predominance of alcohol abuse (264 out of 278).

There were no relevant changes either in the percentage of foreign-born patients, those with a history of previous therapy, with smear-positive sputum, with cavitary disease, with alcohol/drug abuse, or in the total number of patients treated during 1987-1993.

\section{Drug resistance}

Overall resistance to at least one antituberculosis drug was found in $98(9.7 \%)$ patients. Strains of $M$. $t b$ resistant to one drug were found in 59 patients $(5.8 \%)$, and resistance to at least two antituberculosis drugs in 39 patients $(3.9 \%)$. Of the patients with $M . t b$ strains resistant to at least two antibiotics, 27 showed resistance to two drugs and 12 to three or more drugs. SDR resistance to isoniazid $(n=33)$ was followed by resistance to streptomycin $(n=19)$ (table 2$)$. Nearly all patients with multidrug resistance showed resistance to isoniazid $(n=38)$, combined with resistance against streptomycin in 24 patients, against rifampin in 12 , and against pyrazinamide in 9 (table 2).

During 1987 and 1993, SDR showed an increase from $3.9 \%$ in 1988 to $7.8 \%$ in 1991 , followed by a slight decrease to $5.8 \%$ in 1993 (fig. 1). In contrast, MDR showed a continuous increase from 1988 to 1990, followed by slight variations of $4.9 \%$ in 1992 , and $5.8 \%$ in 1993 (fig. 2). The ratio of MDR:SDR increased from $1: 3$ in 1987 to $1: 1$ in 1993.

Table 2. - Proportion of resistant isolates to single antituberculosis drugs

\begin{tabular}{lcc}
\hline Drug & $\begin{array}{c}\text { SDR } \\
(\mathrm{n}=59)\end{array}$ & $\begin{array}{c}\text { MDR } \\
(\mathrm{n}=39)\end{array}$ \\
\hline Isoniazid & 33 & 38 \\
Streptomycin & 19 & 24 \\
Rifampin & 0 & 12 \\
Pyrazinamide & 2 & 9 \\
Ethambutol & 1 & 8 \\
Protionamide & 4 & 13 \\
\hline
\end{tabular}

Number of resistant isolates. SDR: single dose resistance; MDR: multidrug resistance.

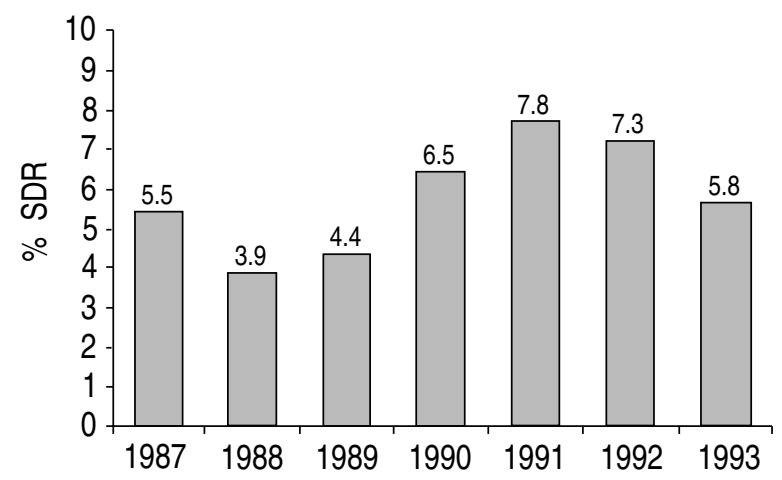

Fig. 1. - Development of single drug resistance in M. tuberculosis strains in Berlin, Germany between 1987 and 1993. Percentages of resistant strains by year. SDR: single-drug resistance.

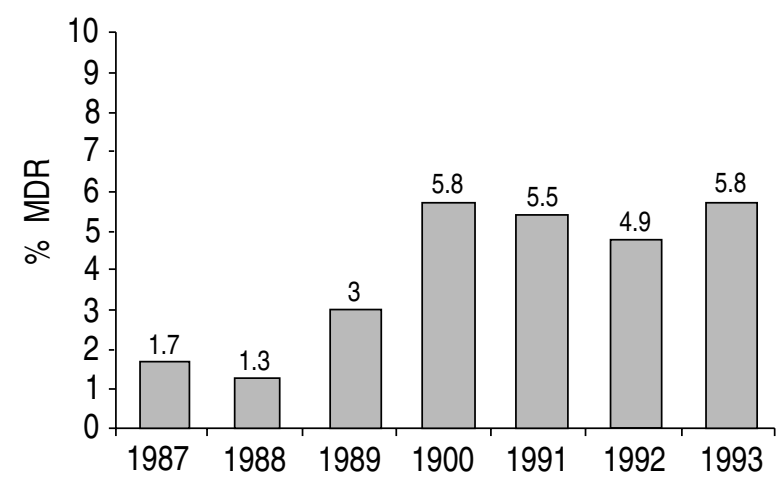

Fig. 2. - Development of multi-drug resistance in M. tuberculosis strains in Berlin, Germany between 1987 and 1993. Percentages of resistance strains by year. MDR: multidrug resistance ( $\geq 2$ drugs tested).

Table 3. - Rates of resistance

\begin{tabular}{lccc}
\hline & $\begin{array}{c}\text { Rate of any } \\
\text { resistance } \\
\%\end{array}$ & $\begin{array}{c}\text { Rate of } \\
\text { SDR } \\
\%\end{array}$ & $\begin{array}{c}\text { Rate of } \\
\text { MDR } \\
\%\end{array}$ \\
\hline $\begin{array}{l}\text { Total population } \\
\text { (n=1011) }\end{array}$ & 9.7 & 5.8 & 3.9 \\
$\begin{array}{l}\text { German-born } \\
\text { (n=675) }\end{array}$ & 6.6 & 4.4 & 2.2 \\
$\begin{array}{l}\text { Foreign-born } \\
\text { (n=336) }\end{array}$ & 15.7 & 8.6 & 7.1 \\
$\begin{array}{l}\text { Previous treatment } \\
\text { (n=153) }\end{array}$ & 20.2 & 9.8 & 10.4 \\
$\begin{array}{l}\text { Previous treatment and } \\
\text { foreign-born } \\
\text { (n=58) }\end{array}$ & 32.7 & 13.8 & 18.9 \\
$\begin{array}{l}\text { Previous treatment and } \\
\text { German-born } \\
\text { (n=95) }\end{array}$ & 12.6 & 7.4 & 5.2 \\
$\begin{array}{l}\text { Cavitary disease } \\
\text { (n=476) }\end{array}$ & 9.7 & 5.7 & 4.0 \\
$\begin{array}{l}\text { Sputum smear positive } \\
\text { (n=642) }\end{array}$ & 9.0 & 5.9 & 3.1 \\
$\begin{array}{l}\text { History of alcohol/drug } \\
\text { abuse } \\
\text { (n=278) }\end{array}$ & 7.9 & 6.1 & 1.8 \\
\hline
\end{tabular}

Percentage of resistant isolates (rate of resistance) in each group of patients. SDR: single-drug resistance; MDR: multidrug resistance. 
Table 4. - Analysis of risk factors for resistant strains of M. tuberculosis

\begin{tabular}{|c|c|c|c|c|c|c|}
\hline Risk factors & $\begin{array}{c}\text { Any resistance } \\
\text { OR } \\
(95 \% \mathrm{CI})\end{array}$ & p-value & $\begin{array}{c}\text { SDR } \\
\text { OR } \\
(95 \% \mathrm{CI})\end{array}$ & p-value & $\begin{array}{c}\text { MDR } \\
\text { OR } \\
(95 \% \mathrm{CI})\end{array}$ & p-value \\
\hline $\begin{array}{l}\text { Previous therapy } v s \\
\text { no previous therapy }\end{array}$ & $\begin{array}{c}\text { 3.0 } \\
(1.8-4.8)\end{array}$ & $<0.0001$ & $\begin{array}{c}2.2 \\
(1.7-4.0)\end{array}$ & 0.0018 & $\begin{array}{c}\mathbf{4 . 5} \\
(2.3-8.8)\end{array}$ & $<0.0001$ \\
\hline $\begin{array}{l}\text { Foreign-born } v s \\
\text { German-born }\end{array}$ & $\begin{array}{c}\mathbf{2 . 6} \\
(1.7-3.9)\end{array}$ & $<0.0001$ & $\begin{array}{c}\mathbf{2 . 2} \\
(1.3-3.6)\end{array}$ & 0.0059 & $\begin{array}{c}\mathbf{3 . 5} \\
(1.8-6.8)\end{array}$ & 0.0002 \\
\hline $\begin{array}{l}\text { Previous therapy in } \\
\text { foreign-born } v s \text { previous } \\
\text { therapy in German-born }\end{array}$ & $\begin{array}{c}\mathbf{3 . 4} \\
(1.5-7.6)\end{array}$ & 0.0036 & $\begin{array}{c}2.43 \\
(0.8-7.1)\end{array}$ & 0.147 & $\begin{array}{c}\mathbf{4 . 6} \\
(1.5-14.4)\end{array}$ & 0.0058 \\
\hline $\begin{array}{l}\text { Cavitary disease } v s \\
\text { no cavitary disease }\end{array}$ & 1.0 & NS & 1.0 & NS & 1.1 & NS \\
\hline $\begin{array}{l}\text { Smear-positive } v s \\
\text { smear-negative }\end{array}$ & 0.9 & NS & 1.0 & NS & 0.6 & NS \\
\hline $\begin{array}{l}\text { Alcohol/drug abuse } \\
v s \text { no abuse }\end{array}$ & 0.8 & NS & 1.0 & NS & 0.4 & NS \\
\hline
\end{tabular}

Odds ratios (ORs) with 95\% confidence intervals $(95 \% \mathrm{CI})$ in parenthesis. P-values denote the significance of the ORs. Bold typed ORs were considered to be significant. SDR: single-drug resistance; MDR: multidrug resistance; Ns: nonsignificant; vs: versus.

\section{Factors associated with drug resistance}

The highest rates of resistance were found in foreignborn patients $(15.7 \%)$, patients with previous therapy $(20.2 \%)$, and patients with a combination of both $(32.7 \%)$ (table 3$)$. This was basically the same for SDR and MDR (table 3). Consequently, the factors associated with a significantly increased risk of resistance to at least one antituberculosis drug were: 1) a history of previous antituberculosis treatment (OR 3.0); and 2) foreign-born status (OR 2.6) (both $\mathrm{p}<0.0001)$ (table 4). As the rate of SDR and MDR were also highest in foreign-born patients and in patients with previous therapy, both of those factors were also significant risk factors for SDR and MDR organisms (table 4). Previous treatment in particular was especially a risk factor for MDR in foreign patients when compared to previously treated German patients (OR 4.6; $\mathrm{p}=0.0058$ ). Due to the small number of patients $(n=8)$, the latter failed to reach statistical significance for SDR $(\mathrm{p}=0.147)$.

On the other hand, factors such as smear-positive tuberculosis or cavitary lung disease, both signs of a major bacilli load in tuberculosis, were not associated with either type of resistance, SDR or MDR. Surprisingly, this was also the case for the risk factor alcohol/ drug abuse, which in our patients did not increase the risk of infection with resistant strains. As the number of patients with MDR and alcohol/drug abuse was very low $(n=5)$, the OR suggest a decreased risk of MDR for patients with abuse, which is clearly not the case.

All risk factors were unrelated to age or gender, and independent of the year of the susceptibility test, since the ORs in age-, gender-, and year of study-matched controls showed no differences in the values displayed above (data not shown).

\section{Acquired versus primary resistance}

The rate of resistance in previously treated patients may reflect the problem of acquired resistance. From 153 patients who had been treated for tuberculosis before entering our study, $31(20.2 \%)$ showed resistance to at least one drug. In foreign-born patients, this rate was significantly higher (19 out of 58), compared to German patients with a history of antituberculosis therapy (12 out of 95) $(\mathrm{p}=0.0036)$ (tables 3 and 5).

The rate of primary resistance in patients without a history of previous therapy $(7.8 \%)$ was lower than the rate of acquired resistance in previously treated patients $(\mathrm{p}<0.0001)$. However, a primary resistance rate of $7.8 \%$

Table 5. - Acquired versus primary resistance of $M$. tuberculosis

\begin{tabular}{lcrrr}
\hline & $\begin{array}{c}\text { Resistant } \\
\text { strains }\end{array}$ & $\begin{array}{c}\text { Sensitive } \\
\text { strains }\end{array}$ & Sum & p-value \\
\hline $\begin{array}{l}\text { Acquired resistance } \\
\text { Foreign-born }\end{array}$ & 19 & 39 & 58 & \\
German-born & 12 & 83 & 95 & \\
Sum & 31 & 122 & 153 & 0.0036 \\
& & & & \\
Primary resistance & & & & \\
Foreign-born & 34 & 244 & 278 & \\
German-born & 33 & 547 & 580 & \\
Sum & 67 & 791 & 858 & 0.0016 \\
\hline
\end{tabular}

Resistance of $M$. $t b$ was considered to be acquired resistance in patients with a history of previous antituberculosis therapy. Resistance in patients without any previous antituberculosis treatment was considered to be primary resistance. P-values denote significant differences between foreign- and Germanborn patients (Fisher's exact test). 
demonstrates a substantial amount of transmission of resistant $M . t b$ strains in the population investigated. Again, the rate of primary resistance was significantly higher in foreign-born patients $(12.2 \%)$, compared to $5.6 \%$ in German patients $(\mathrm{p}=0.0016)$ (table 5).

\section{Discussion}

In this retrospective survey, we found an increasing rate of multidrug-resistant organisms in patients with pulmonary tuberculosis treated in our hospital since 1987. In 1993, half of our patients with resistance showed resistance to two or more drugs, compared to $25 \%$ in 1987. This is a dramatic change compared to a survey carried out at our institution between 1972 and 1975 [21], when resistance to one or more drugs was observed in $6.1 \%$ of 1,037 strains investigated [2]. At that time, single-drug resistance with a frequency of $4.4 \%$ accounted for more than $70 \%$ of all resistance types, and multidrug resistance was observed in only $1.7 \%$ of all cases.

Explanations for the increased rates of resistance in our patients are difficult to determine, since we did not observe any relevant changes in the percentage of patients with risk factors during the 7 study years. However, some possible factors should be discussed.

For German society, the most relevant change in the last few years was the reunification of West and East Germany in 1989. We do not believe that this event had an impact on our results, since the rate of resistance in East Germany was reported for the years 1980-1988 and was found to be very low (SDR $\leq 3 \%$; MDR $<1.0 \%$ ) [22]. Another possible explanation may be that increasing poverty in Germany has influenced the spread of resistance by increasing the number of patients at risk for transmission of resistant strains of $M$. $t b$, and decreasing patient compliance to antituberculosis therapy, as demonstrated in New York City [11]. However, we were not able to quantify this possible impact on the results of our study from the data obtained.

Since $15.7 \%$ of strains showed resistance to at least one drug in foreign-born patients, whereas the rate was only $6.6 \%$ in German-born patients, one could speculate at to whether this plays an important role in the problem of resistance. However, although immigration to Berlin may be responsible for the higher number of resistant cases compared to the situation in the whole of Germany, immigration alone cannot be responsible for the observed increase of resistance in our patients, since the percentage of foreign patients treated for tuberculosis in our hospital did not change significantly between 1987 and 1993. Moreover, we also observed an increase in resistance rates in our German patients.

A similar trend of increasing resistance of $M$. $t b$ between 1987 and 1991 has recently been reported in New York City [23]. Although the overall incidence of resistance in our study was much lower than in New York City, where the overall rate of resistance in a 1991 survey was $33 \%$, and the rate in previously treated patients $44 \%$ [11], our data demonstrated some similar features. As in New York City, the rate of resistant $M$. $t b$ in our previously treated patients was higher than in those who had never been treated.

Another similarity to the situation in the United States is the difference in resistance between major cities and the rest of the country. In 1991 and 1992, the rate of MDR in Germany was reported to be $2.9 \%$ [3] in comparison to $5.2 \%$ at our institution. One reason for the difference between Berlin and the rest of Germany may be the increased number of foreign-born people living and working in Berlin compared to other parts of Germany. Since an increasing rate of resistance could be observed in countries with a lower level of medical care [24], for example Puerto Rico [25], Africa [26], and Korea [27], migration may be an important factor in the spread of resistant $M$. $t b$ organisms, as was recently shown in England [28]. Another explanation for the difference observed between major cities and rural communities might be the presumably higher transmission rate of resistant $M . t b$ strains in urban as compared to rural populations.

There are two major differences between the situation in Berlin and in New York City. Firstly, in contrast to the findings in New York City, where status of foreign-born or recent immigration was not related to resistance [11], we found that the risk for SDR and MDR was clearly connected to the origin of our patients. This discrepancy may be explained by the low incidence of resistance in German patients compared to patients born in the US, rather than in differences between the rate of resistance of foreign-born patients treated in the US or in Germany. The second major difference between the situation in Germany and the US is the impact of HIV infection on tuberculosis. Co-infection with $M$. $t b$ and HIV is only a minor problem in Germany today [1, 29], and was below $2 \%$ in our institution in recent years. This is quite different from the situation in the US, where the contribution of HIV infection to the excessive number of tuberculosis cases was judged to be as high as 18,000 cases between 1985 and 1991 [5]. However, a further increase in HIV infection in Europe may aggravate this problem in the near future [30].

Finally, when we compared the situation in Berlin to the US, it must be mentioned that unlike the definition of MDR in the US, where MDR always denotes resistance to at least isoniazid and rifampin $[11,23]$, we used a wider definition of MDR. We feel that resistance to at least two first-line drugs will cause such severe treatment problems that it is justifiable to take more serious note of this type of resistance than SDR.

There is evidence that most of the resistance cases that we observed were primary resistance due to the transmission of resistant strains, since the patients did not receive antituberculosis therapy before entering the study. The substantial rate of $7.8 \%$ for primary resistance underlines the need for susceptibility testing in previously untreated patients. Although we found the number of primary resistance to be twice as high as acquired resistance, the risk of any kind of resistance is much higher in patients who had previously received antituberculosis therapy. This kind of resistance might be 
due to acquired resistance. However, with regard to acquired resistance, our study has several limitations, and, thus, leads to some speculation. Firstly, we did not know whether or not the previously treated patients suffered from infection with susceptible $M$. $t b$ strains at the time of previous treatment. Secondly, our information was incomplete regarding substances previously taken and a possible noncompliance to the therapy. And finally, we cannot exclude a new infection with resistant strains in our previously treated patients.

However, the fact that the amount of bacilli load, which normally correlates to the probability of natural resistant bacilli [31], did not correlate to resistance rates supports the opinion that primary and acquired resistance are the most important types of resistance, and that natural resistance plays only a minor role [32].

The treatment of MDR tuberculosis is a major problem, and the results of all approaches in this field are very discouraging [33]. Therefore, every effort must be made to avoid acquired resistance and to avoid further development in SDR patients. In addition to therapeutic approaches, there is a need for new techniques to detect resistance of $M$. $t b$ as early as possible [34]. Regarding noncompliance as the main cause of resistance, directly observed therapy has also been shown to be a valuable tool, especially in patients at risk for noncompliance.

Some conclusions can be drawn from the results of our studies. Firstly, since patients with a history of antituberculosis therapy have a high risk of acquired resistance, one should consider an initial regimen comprising four drugs, two of which should never have been given previously. Secondly, patients coming from countries with a known high rate of resistance should also be treated with four drugs, whilst for patients from countries with a known low incidence of resistance a three drug regimen may be acceptable. Thirdly, susceptibility testing is clearly mandatory in every case with one of the known risk factors for resistance. However, in our opinion the substantial rate of primary resistance also justifies routine susceptibility testing in every patient with tuberculosis. Finally, foreign-born patients or those with a history of previous treatment should be very carefully monitored throughout the entire therapy to avoid the development of further resistance.

\section{References}

1. Deutsches Zentralkomitee zur Bekämpfung der Tuberkulose. 17. Informationsbericht. Mainz, pmi Verlag, 1990.

2. Matthiesen W, Kind A, Göbel D. Epidemiologie der Primärresistenz von Tuberkulosebakterien in der Bundesrepublik Deutschland einschlie $\beta$ lich Berlin im Beobachtungszeitraum 1972-1975. Prax Pneumol 1977; 31: 890-898.

3. Arbeitskreis Mykobakterien. Erhebung zur Resistenzlage der Tuberkulosebakterien in Deutschland für das Jahr 1991 und 1992. Pneumologie 1994; 48: 28-29.

4. Reichman LB. The U-shaped curve of concern. Am Rev Respir Dis 1991; 144: 741-742.

5. Bloom BR, Murray CJL. Tuberculosis: commentary on a reemergent killer. Science 1992; 257: 1055-1064.
6. Riley LW. Drug-resistant tuberculosis. Clin Infect Dis 1993; 17: 442-446.

7. Edlin BR, Tokars JI, Grieco MH, et al. An outbreak of multidrug-resistant tuberculosis among hospitalized patients with the acquired immunodeficiency syndrome. $N$ Engl J Med 1992; 326: 1514-1521.

8. Fischl MA, Daikos GL, Uttamchandani RB, et al. Clinical presentation and outcome of patients with HIV infection and tuberculosis caused by multiple-drug-resistant bacilli. Ann Intern Med 1992; 117: 184-190.

9. Small PM, Shafer RW, Hopewell PC, et al. Exogenous reinfection with multidrug-resistant Mycobacterium tuberculosis in patients with advanced HIV infection. $N$ Engl J Med 1993; 328: 1137-1144.

10. Chawla PK, Klapper PJ, Kamholz SL, Pollack AH, Heurich AE. Drug-resistant tuberculosis in an urban population including patients at risk for human immunodeficiency virus infection. Am Rev Respir Dis 1992; 146: 280-284.

11. Frieden TR, Sterling T, Pablos Mendez A, Kilburn JO, Cauthen GM, Dooley SW. The emergence of drugresistant tuberculosis in New York City. $N$ Engl J Med 1993; 328: 521-526.

12. Neville K, Bromberg A, Bromberg R, Bonk S, Hanna BA, Rom WN. The third epidemic of multidrug-resistant tuberculosis. Chest 1994; 105: 45-48.

13. Center of Disease Control. Meeting the challenge of multidrug-resistant tuberculosis: summary of a conference. MMWR Morb Mortal Wkly Rep 1992; 41: 51-57.

14. American Thoracic Society. Diagnostic standards and classification of tuberculosis. Am Rev Respir Dis 1990; 142: 725-735.

15. Schluger NW, Rom WN. Current approaches to the diagnosis of active pulmonary tuberculosis. Am J Respir Crit Care Med 1994; 149: 264-267.

16. Kent TP, Kubica GP. A guide for the level III laboratory. Atlanta; Centers for Disease Control, 1985.

17. Deutsches Zentralkomitee zur Bekämpfung der Tuberkulose. Die Bakteriologie der Tuberkulose. Pneumologie 1991; 45: 753-774.

18. Woods GL, Witebsky FG. Current status of mycobacterial testing in clinical laboratories: results of a questionnaire completed by participants in the College of American Pathologists Mycobacteriology E survey. Arch Pathol Lab Med 1993; 117: 876-884.

19. Deutsche Gesellschaft für Hygiene und Mikrobiologie. Isolierung und Identifizierung von Mycobacteriaceae. $\mathrm{Zbl}$ Bakt 1989; 272: 110-140.

20. Gardner MJ, Altman DG. Statistics with confidence. London, British Medical Journal, 1989.

21. Hussels H. Die Häufigkeit der primären Resistenz von Tuberkulosebakterien in der Bundesrepublik Deutschland einschließlich Berlin (West) im Beobachtungszeitraum 1972-1975. Prax Pneumol 1977; 31: 664-670.

22. Kalich R. Resistenzhäufigkeit von M. tuberculosis bei stationär behandelten Patienten in Ostdeutschland. Pneumologie 1991; 45: 725-728.

23. Sepkowitz KA, Telzak EE, Recalde S, Armstrong D, and the New York City Area Tuberculosis Working Group. Trends in the susceptibility of tuberculosis in New York City, 1987-1991. Clin Infect Dis 1994; 18: 755-759.

24. Glennon J, Fegan D. Treating tuberculosis in developing countries. Br Med J 1992; 305: 954-955.

25. Grandes G, Lopez de Munain J, Diaz T, Rullan JV. Drug-resistant tuberculosis in Puerto Rico, 1987-1990. Am Rev Respir Dis 1993; 148: 6-9.

26. Braun MM, Kilburn JO, Smithwick RW, et al. HIV 
infection and primary resistance to antituberculosis drugs in Abidjan, Cote d'Ivoire. AIDS 1992; 6: 1327-1330.

27. Hong YP, Kim SJ, Kwon DW, Chang SC, Lew WJ, Han YC. The sixth Nationwide Tuberculosis Prevalence Survey in Korea, 1990. Tuber Lung Dis 1993; 74: 323-331.

28. Yates MD, Grange JM. A bacteriological survey of tuberculosis due to the human tubercle bacillus (Mycobacterium tuberculosis) in south east England: 19841991. Epidemiol Infect 1993; 110: 609-619.

29. Pankow W, Kohl FV, von Wichert P. HIV-Infektion und Tuberkulose. Internist 1990; 31: 282-287.

30. Styblo K. The impact of HIV infection on the global epidemiology of tuberculosis. Bull Int Union Tuberc Lung Dis 1991; 66: 27-32.
31. Weyer K, Kleeberg HH. Primary and acquired drug resistance in adult black patients with tuberculosis in South Africa: results of a continuous national drug resistance surveillance programme involvement. Tuberc Lung Dis 1992; 73: 106-112.

32. Rastogi N, David HL. Mode of action of antituberculous drugs and mechanisms of drug resistance in Mycobacterium tuberculosis. Res Microbiol 1993; 144: 133143.

33. Iseman MD. Treatment of multidrug-resistant tuberculosis. N Engl J Med 1993; 329: 784-791.

34. Jacobs WR Jr, Barletta RG, Udani R, et al. Rapid assessment of drug susceptibilities of Mycobacterium tuberculosis by means of luciferase reporter phages. Science 1993; 260: 819-822. 